\title{
Physicochemical Characteristics of Particulate Matter Emitted from the Oxygenated Fuel/Diesel Blend Engine
}

\author{
Hao Yang ${ }^{1}$, Yongqiang Zhang ${ }^{1}$, Cong $\mathrm{Li}^{\mathbf{1}^{*}}$, Yu Fang ${ }^{1}$, Xinghu Li ${ }^{2}$ \\ ${ }^{1}$ School of Mechanical and Automotive Engineering, Shanghai University of Engineering \\ Science, Shanghai 201620, China \\ ${ }^{2}$ School of Transportation Science and Engineering, Beihang University, Beijing 100191, China
}

\begin{abstract}
The physicochemical characteristics of particulate matter (PM) produced by polyoxymethylene dimethyl ethers $\left(\mathrm{PODE}_{2-4}\right)$ /diesel blended fuel at different blend ratios was characterized using transmission electron microscopy (TEM), Fourier transform infrared spectroscopy (FTIR) and $X$-ray photoelectron spectroscopy (XPS). TEM analysis indicated that the overall size of PM decreased with an increasing $P O D E_{2-4}$ concentration. TEM images using fractal theory showed that the fractal dimension of $P M$ increased as the $\mathrm{PODE}_{2-4}$ blending ratio increased. These trends increased the oxidation activity. FTIR was used to analyze the aliphatic $\mathrm{C}-\mathrm{H}$ on the surface of PM and found that the ratio $I_{\mathrm{C}-\mathrm{H}} / I_{\mathrm{C}=\mathrm{C}}$ and the aliphatic $\mathrm{C}-\mathrm{H}$ functional group on the surface of PM decreased with an increasing $\mathrm{PODE}_{2-4}$ blending ratio. According to XPS data, with increments of the $\mathrm{PODE}_{2-4}$ blending ratio, the contents of $\mathrm{O} / \mathrm{C}, \mathrm{sp}^{3} / \mathrm{sp}^{2}, \mathrm{C}-\mathrm{OH}, \mathrm{C}=\mathrm{O}$ and total oxygen-containing functional groups of the PM increased, demonstrating that the oxygen-containing functional group and disorder of the PM nanostructure was correlated with a faster oxidation rate. Results thus demonstrated that the addition of $\mathrm{PODE}_{2-4}$ can affect the nanostructure and oxidation activity of PM, making it easier to oxidize to reduce environmental pollution.
\end{abstract}

Keywords: Particulate matter, Physicochemical characteristics, Transmission electron microscopy, Fourier transform infrared spectroscopy, X-ray photoelectron spectroscopy

\section{INTRODUCTION}

Received: July 20, 2021

Revised: October 12, 2021

Accepted: October 13, 2021

${ }^{*}$ Corresponding Author:

licong@sues.edu.cn

Publisher:

Taiwan Association for Aerosol Research

ISSN: $1680-8584$ print

ISSN: 2071-1409 online

cc) Copyright: The Author(s). This is an open access article distributed under the terms of the Creative Commons Attribution License (CC BY 4.0), which permits unrestricted use, distribution, and reproduction in any medium, provided the original author and source are cited.
The particulate matter (PM) emitted by diesel engines is one of the primary factors that lead to hazy weather, which can cause serious environmental pollution and harm human health (Rouleau et al., 2013; Shi et al., 2019; Xian et al., 2019; Yan et al., 2021). Most PM consists of fine particles, and fine particles (especially $\mathrm{PM}_{2.5}$ ) can pose a serious threat to health. Many epidemiological studies have shown that long-term exposure to $\mathrm{PM}_{2.5}$ can increase the risk of respiratory and cardiovascular diseases (Chen et al., 2015; Di et al., 2017; Li et al., 2017; YitshakSade et al., 2017). Therefore, the PM emitted from diesel engines has always been an important research topic.

To reduce environmental pollution and harm to public health caused by diesel engines, oxygenated fuel has become a prospective solution because it can improve the combustion condition of engines and decrease PM emissions (Awad et al., 2018; Nayyar et al., 2019). As a new type of renewable oxygen-containing fuel, polyoxymethylene dimethyl ethers ( $P O D E_{n}$ ) is actually a low molecular weight acetal-based polymer that is synthesized by dimethyl ether, methanol and paraformaldehyde as raw materials (Ren et al., 2019). PODE $n$ has a high cetane number and excellent ignition performance, which can reduce engine noise and yield gentle operation. $P O D E_{n}$ is a liquid fuel under standard conditions, which is simpler than dimethyl ether storage. In addition, due to the absence of $\mathrm{C}-\mathrm{C}$ bonds and high oxygen content in the PODE $\mathrm{E}_{\mathrm{n}}$ molecule, the engine achieves 
fine combustion performance and reduces harmful PM emissions (Liu et al., 2015; Yang et al., 2016). As an additive to diesel, PODE $E_{n}$ has excellent application prospects (Wang et al., 2018).

TEM can be used to observe the nanomorphology of diesel exhaust particles. Li and Wang (2018) produced photos of diesel and five different biodiesel particles, and discovered that the primary carbon particles were primarily spherical, and the arrangement of biodiesel PM was relatively compact, while the arrangement of diesel particles was relatively loose. Qu et al. (2016) viewed the nanostructure of biodiesel exhaust particles in gutter oil and suggested that PM was distributed in a chain shape. With the increase of biodiesel blending proportion, the primary particles became more compact, and the average diameter of the PM decreased. Zhu et al. (2016) reported an image of biodiesel-pentanol blended fuel and showed that the diameter of primary particles decreased with increasing pentanol proportion in a blended fuel.

FTIR can be applied to study the composition of functional groups on the surface of diesel particles. Omidvarborna et al. (2016) compared the surface functional groups of soybean methyl ester, tallow oil, waste cooking oil and diesel emission particles, and results showed that aliphatic $\mathrm{C}-\mathrm{H}$ functional groups were an important part of the surface functional groups of biodiesel particles. Salamanca et al. (2012) studied the surface functional groups of palm oil biodiesel particles with different blending ratios and found that the blending ratio of biodiesel increased and the content of aliphatic functional groups on the surface of PM decreased. The authors believed that the increase in oxygen content made the oxidation of PM easier, which led to a lower content of aliphatic functional groups. Wang et al. (2019) investigated the surface functional groups of diesel particles under different loads and found that with increasing engine load, the relative content of aliphatic $\mathrm{C}$ - $\mathrm{H}$ functional groups of diesel particles decreased, while the engine speed had no significant effect on $\mathrm{C}-\mathrm{H}$ functional groups.

XPS is the most commonly used technique for PM surface analysis (Atzei et al., 2014; Guascito et al., 2015). XPS can determine the composition of the elements in a sample by determining electron binding energy and can be used to analyze the functional group distribution of the elements and the degree of carbon atom hybridization. Savic et al. (2016) analyzed the microstructure of microalgae B50 and B5 particles and discovered that there were three elements on the surface of exhaust PM, oxygen, carbon and silicon. As the proportion of biodiesel increased in a blended fuel, the oxygen content of the fuel surface increased, and the arrangement of PM became more disordered. Lapuerta et al. (2019) studied the functional groups on the surface of butanol mixed fuel particles and found that with the increase of butanol content in the fuel, the oxygencontaining functional groups on the surface of exhaust PM increased.

Few studies have investigated the PM emissions of diesel engines fueled with $\mathrm{PODE}_{\mathrm{n}} /$ diesel blends. In this paper, TEM, FTIR, XPS experiments and fractal theory were used to study the variation regularity of organic functional groups, the hybridization ratio of carbon and nanostructures on the surface of diesel particles fueled with different blending radios of PODEn/diesel blended fuel; volume ratios of $0 / 100,10 / 90,20 / 80$, which are referred to as P0, P10 and P20. TEM experiments and fractal theory primarily investigated the particle size to describe the effect of the PODE blending ratio on the oxidation reactivity of blended fuel particles. FTIR and XPS experiments primarily focused on the surface functional group content of PM. The results of the XPS experiment on the surface oxygen-containing functional groups of PM supported the conclusion that the content of $\mathrm{C}-\mathrm{H}$ aliphatic functional groups on the surface of PM decreased in the FTIR experiment. In contrast, results also verified the accuracy of the XPS test conclusion. The purpose of those experiments was to study the oxidation activity of blended fuel exhaust particulates under different blending proportions, and to explore the difficulty of regeneration of the particulate filter.

\section{METHODS}

\subsection{PM Sampling Procedure and Preparation}

The engine used in this experiment was the single-cylinder four-stroke R180 diesel engine produced by the Changchai Company. The primary parameters of the engine are shown in Table 1. The fuel oxygenating additive used in this paper was $\mathrm{PODE}_{2-4}$, which was made by blending $\mathrm{PODE}_{2}, \mathrm{PODE}_{3}$ and $\mathrm{PODE}_{4}$ according to mass distributions of $2.55 \%, 88.9 \%$ and $8.48 \%$, with diesel as the base fuel. Sampling was performed under $5 \%$ and $100 \%$ working conditions at $1800 \mathrm{r} \mathrm{min}^{-1}$. 
Table 1. Main specifications of diesel engine.

\begin{tabular}{ll}
\hline Model & Changchai R180 \\
\hline Number of cylinders & Single-cylinder \\
Rated power $(\mathrm{kW})$ & $5.67\left(2600 \mathrm{rmin}^{-1}\right)$ \\
Rated torque $(\mathrm{N} \cdot \mathrm{m})$ & $23.4\left(1800 \mathrm{r} \mathrm{min}^{-1}\right)$ \\
Bore $\times$ Stroke $(\mathrm{mm} \times \mathrm{mm})$ & $80 \times 80$ \\
Displacement volume $(\mathrm{mL})$ & 402 \\
Compression ratio & $21: 1$ \\
Injection pressure $(\mathrm{MPa})$ & $13.72 \pm 0.5$ \\
\hline
\end{tabular}

Samples were collected in the exhaust pipe $1.2 \mathrm{~m}$ away from the engine exhaust manifold using the metal-filter direct sampling method. In the experiment, the multilayer metal wire mesh was placed in the exhaust pipe, and the diesel exhaust particles were filtered by the metal filter, achieving a similar effect to that of DPF, thus obtaining PM samples similar to those of DPF. Diesel blends' exhaust particles were collected at different concentrations in sample bottles and then sealed. Before each test, the engine was preheated for 20 minutes.

For PM preparation, ultrasonic vibration and centrifugal separation were used. First, the collected diesel exhaust particles were put into ethanol solution and subjected to ultrasonic vibration for 30 minutes to ensure complete dissolution. Then, the mixed solution was transferred directly into the centrifuge tube and centrifuged at $4000 \mathrm{r} \mathrm{min}^{-1}$ for 1 hour. Under the action of centrifugal force, the solid-liquid was stratified, and the separated precipitates were clean PM without a soluble organic fraction (SOF). To completely remove the SOF from the PM surface, ultrasonic vibration and centrifugal separation were repeated three times. Finally, the prepared particles were sealed and stored away from light.

\subsection{Experimental Apparatus and Procedure}

\subsubsection{Transmission electron microscopy}

The TEM method was performed with a Tecnai $G^{2} 20$ field-emission transmission electron microscope produced by FEI Company in the United States to analyze the nanostructure characteristics of PM. Its point resolution was $0.24 \mathrm{~nm}$, a LaB 6 filament was used, the accelerating voltage was $200 \mathrm{kV}$, and the maximum magnification was 1.03 million times. TEM was used to analyze the prepared samples, and a nanostructure diagram of diesel exhaust particles was obtained.

\subsubsection{Fractal dimension}

The complex and irregular microstructure of PM had self-similar fractal characteristics. PM's nanostructure was analyzed using fractal dimensions, and the specific number can indicate the density of PM.

Brasil et al. (1999) calculated the fractal dimension $D_{f}$ of diesel engine exhaust PM using Eq. (1):

$N=k_{g}\left(\frac{2 R_{g}}{D_{p}}\right)^{D_{f}}$

Taking the logarithm of both sides of Eq. (1) yields:

$\lg N=D_{f} \lg \left(2 R_{g} / D_{p}\right)+\lg k_{g}$

where $N$ is the number of primary carbon particles; $D_{p}$ is the diameter of primary carbon particles; and $k_{g}$ is the pre-exponential factor. For the PM radius of gyration $R_{g}$, the following equation can be used

$R_{g}=\sqrt{\frac{1}{N} \sum_{i=1}^{N} r_{i}^{2}}$ 
where $r_{i}$ is the distance from the ith primary carbon particle center to the PM centroid.

When Eq. (3) was used to calculate the PM radius of gyration $R_{g}$, it was difficult to measure the PM centroid accurately due to stacking and overlapping among the primary carbon particles; thus, it was not realistic to directly measure the PM radius of gyration. Therefore, Brasil et al. (1999) discovered that electron microscope images of PM could be analyzed using indirect estimation of the PM radius of gyration. The relationship between the PM radius of gyration and the maximum projected length $L$ is shown in Eq. (4):

$L /\left(2 R_{g}\right)=1.50 \pm 0.05$

The number of primary carbon particles $N$ was also indirectly estimated from the TEM image of PM, and its relationship with the projected area of primary carbon particles $A_{p}$ and the projected area of particles $A_{a}$ is shown in Eq. (5):

$N=k_{a}\left(\frac{A_{a}}{A_{p}}\right)^{\alpha}$

Using Image-Pro Plus 6.0 software, the particle projected area $A_{a}$ and the primary carbon particle diameter $D_{p}$ can be directly obtained. The projected area $A_{p}$ of primary carbon particles can be obtained using the equation, where $k_{a}$ refers to the pre-exponential factor of the projected area, and $\alpha$ refers to the empirical index of the projected area. Based on the results reported by Köylü et al. (1995), $k_{a}$ and $\alpha$ were set equal to 1.16 and 1.10, respectively, and their standard deviations were 0.01 and 0.002 , respectively.

\subsubsection{Fourier transform infrared spectroscopy}

FTIR was performed using a Nicolet 6700 advanced Fourier transform infrared spectroscope that was produced by Thermo Fisher Scientific Company of the United Statesto analyze the chemical composition of substances of interest. The acquisition resolution was $1 \mathrm{~cm}^{-1}$, the number of scans was 32 , and the spectral range was $4000-400 \mathrm{~cm}^{-1}$. Before analyzing the data, OMNIC software was used for automatic baseline correction and spectral smoothing.

To study the surface functional groups of diesel emission particles, FTIR technology was used to detect and analyze the hydrocarbon functional groups of different fuel PM.

\subsubsection{X-ray photoelectron spectroscopy}

XPS was performed using a ESCALAB 250Xi multifunctional high-performance X-ray photoelectron spectroscope that was produced by Thermo Fisher Scientific Company of the United Statesto analyze the elements, functional group distribution and the degree of carbon atom hybridization on the sample surface. The charge effect correction used C1s (284.60 eV). The number of energy steps of PM full spectrum scanning was 1371, the number of scans was 1, the energy step size was $1.000 \mathrm{eV}$, and the pass energy was $100.0 \mathrm{eV}$. When conducting fine spectral scanning of carbon elements, the energy step size was $0.100 \mathrm{eV}$, the pass energy was $30.0 \mathrm{eV}$, the number of scans was 5 times, the sample analysis area was $0.7 \times 0.3 \mathrm{~mm}^{2}$, the working voltage was $15 \mathrm{kV}$, and the power was $400 \mathrm{~W}$.

In this XPS experiment, the elemental composition on the surface of $\mathrm{PM}$, the $\mathrm{sp}^{3} / \mathrm{sp}^{2}$ hybridization ratio of carbon atoms, and the $\mathrm{C}-\mathrm{OH}$ and $\mathrm{C}=\mathrm{O}$ functional groups were analyzed. The $\mathrm{C}-\mathrm{OH}, \mathrm{C}=\mathrm{O}$ functional groups and the hybridization information of carbon atoms on the surface were determined by splitting and resolving the C1s peak in the XPS full-spectrum scanning image.

\section{RESULTS AND DISCUSSION}

\subsection{Nanomorphology of PM Samples}

Fig. 1 shows that some regions of exhaust PM are darker in color, which is caused by the stacking of several primary carbon particles, thus blurring the outline of a single primary carbon particle. According to the TEM images and the PM density, and the PM in the exhaust gas of PO 

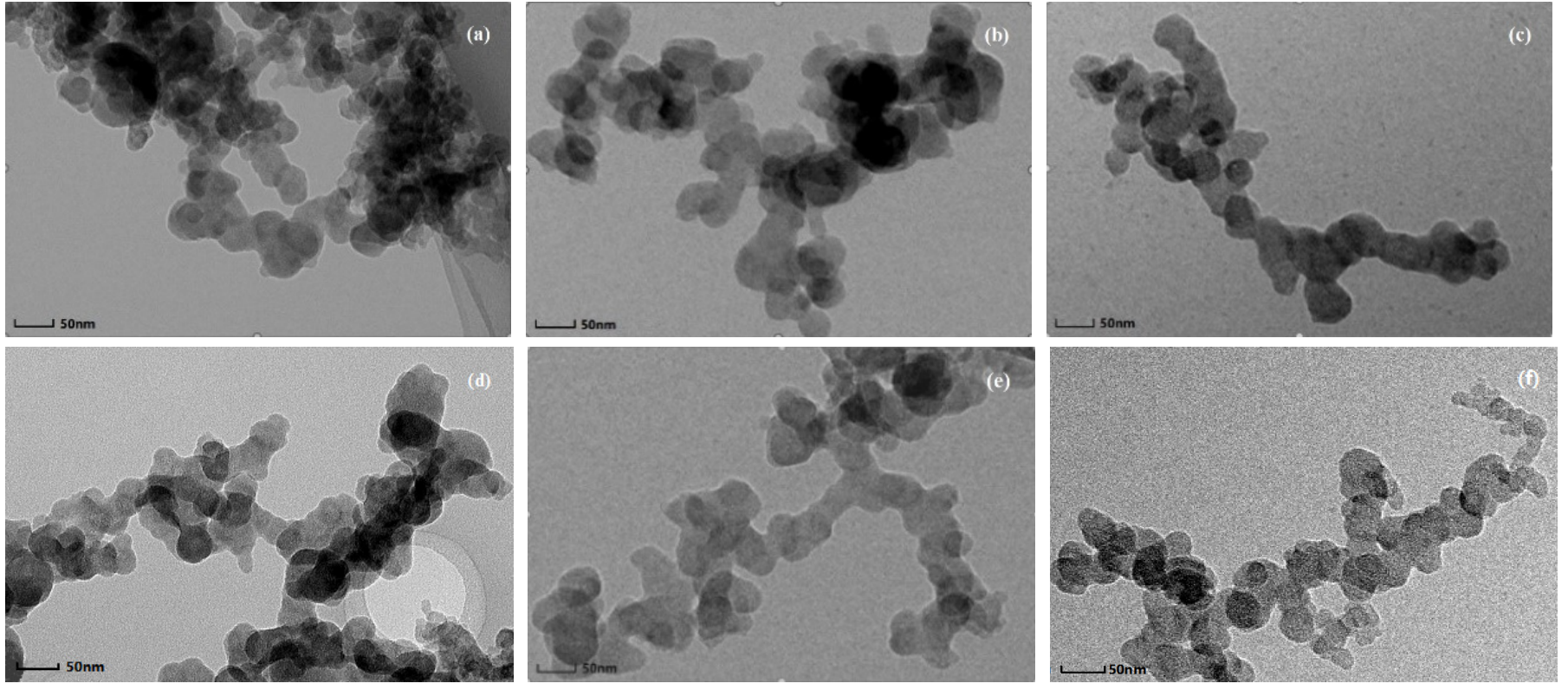

Fig. 1. TEM images of PM samples: (a) P0, (b) P10, (c) P20 at low load and (d) P0, (e) P10, (f) P20 at high load (magnification of $50,000 \times)$.

is the loosest. As the blending ratio of $\mathrm{PODE}_{2-4}$ increases, $\mathrm{PM}$ becomes smaller and more compactly arranged in terms of overall size. The quantities of branched chains and primary carbon particles also decrease significantly, and the chain length decreases gradually. PODE 2 is a type of oxygenated fuel that can encourage complete fuel combustion, reducing PM generation. Less PM will lower the probability of collision between primary carbon particles, thus reducing the number of PM required to form a chain shape, which is difficult to combine into large-size PM (Gao et al., 2019). Smaller PM is known to be more easily oxidized, which is conducive to DPF regeneration.

\subsection{Fractal Dimension Fitting and Parameter Analysis}

Image-Pro Plus 6.0 software is used to manually define each primary carbon particle in the TEM image to determine the primary carbon particle diameter $D_{p}$, the maximum projected length $L$ of particles, the projected area $A_{p}$ of primary carbon particles and the particles projected area $A_{a}$, as shown in Fig. 2.

Using the equations above, $N$ and $R_{g}$ of the PM can be obtained; thus, the $\lg N-\lg \left(2 R_{g} / D_{p}\right)$ coordinate diagram can be drawn, as shown in Fig. 3. Using Origin Software for multipoint fitting, a straight line can be obtained. The particle fractal dimension $D_{f}$ can be represented by the slope

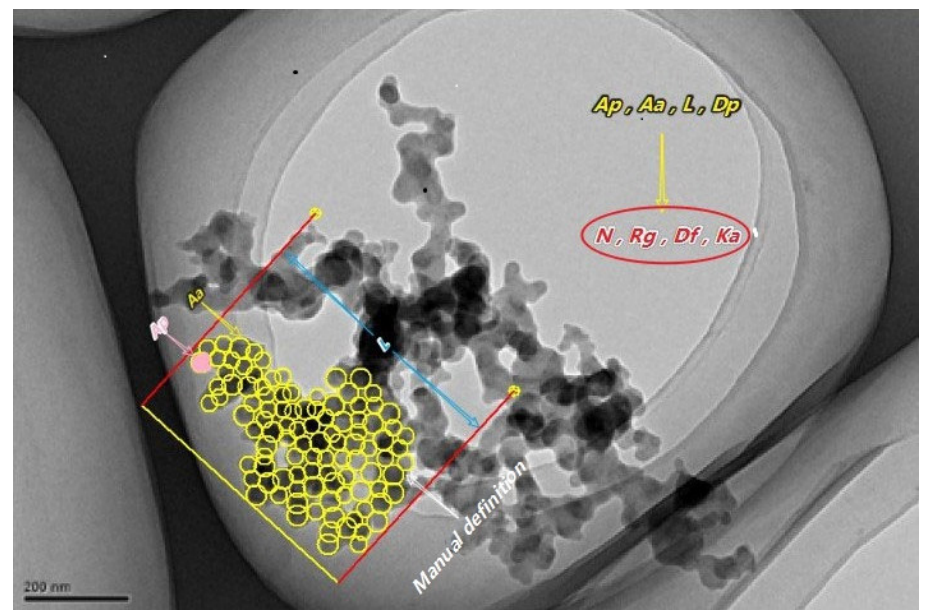

Fig. 2. Schematic of parameter acquisition. 

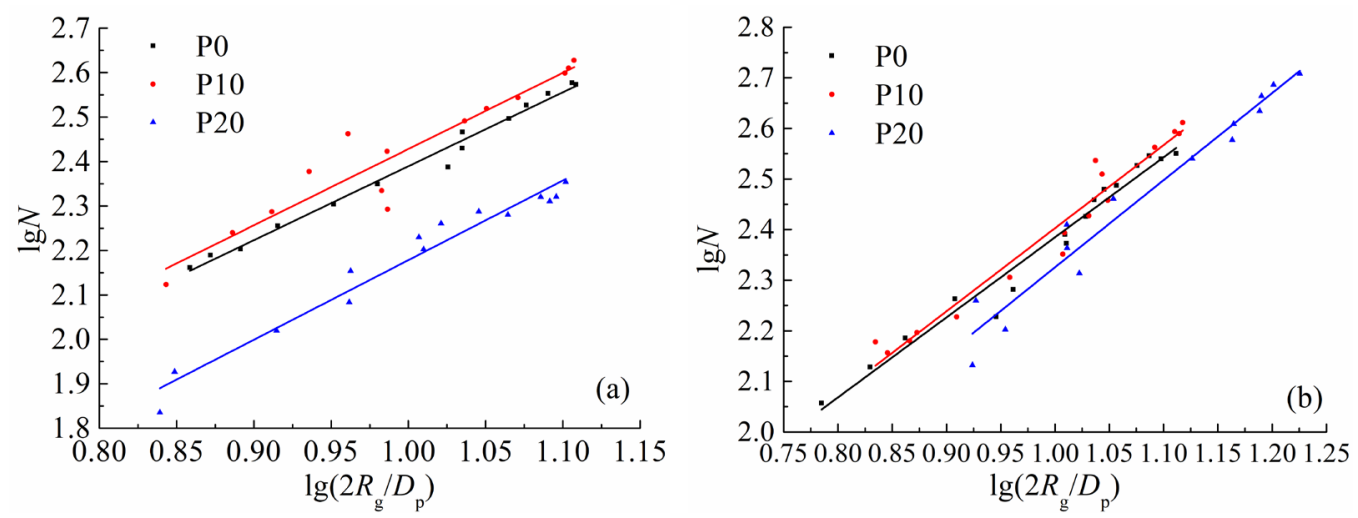

Fig. 3. Fitting straight line graphs of PM sample fractal dimensions: (a) P0, P10, P20 at low load and (b) PO, P10, P20 at high load.

Table 2. Fractal dimension of PM samples.

\begin{tabular}{lllll}
\hline & PM & P0 & P10 & P20 \\
\hline$D_{f}$ & Low load & 1.66 & 1.71 & 1.79 \\
& High load & 1.58 & 1.64 & 1.72 \\
\hline
\end{tabular}

of the straight line, and the pre-exponential factor $k_{g}$ can be represented by the intercept of the straight line.

Figs. 3(a) and 3(b) show the fitting straight line graphs of the exhaust PM fractal dimension of P0, P10 and P20 under low and high loads, respectively. The fractal dimension varies from 1.58 to 1.79, and the specific values are shown in Table 2. Comparison with the data in Table 2 shows that the fractal dimension of PM under high and low loads increases with an increasing PODE $2-4$ blending ratio. At low load, the fractal dimension of PM emitted from P10 and P20 increases by 0.05 and 0.08 compared with PO, and at high load, the fractal dimension of PM emitted from P10 and P20 increases by 0.06 and 0.08 compared with P0. The fractal dimension can describe the density of PM: the larger the fractal dimension is, the higher the overlapping rate and the closer the arrangement is. This result may occur because PODE $2-4$ is a type of oxygenated fuel, and with more PODE $2-4$, the oxygen content of the blended fuel increases, making the fuel burn more completely. Smaller PM will be oxidized, and the amount of PM will decrease. As a result, the probability of collision and combination between primary particles decreases, and it is not easy to connect, merge or agglomerate particles; thus, it is difficult to form a larger PM.

\subsection{Results of the FTIR Analysis}

Fig. 4 shows the FTIR spectra of the P0, P10 and P20 exhaust PM samples under high and low loads. Generally, the asymmetric methylene peak near $2920 \mathrm{~cm}^{-1}$ in the infrared spectrum is attributed to $\mathrm{C}-\mathrm{H}$ binding, and the aromatic ring peak near $1645 \mathrm{~cm}^{-1}$ is attributed to $\mathrm{C}=\mathrm{C}$ binding. The relative content of aliphatic $\mathrm{C}-\mathrm{H}$ functional groups is determined by two characteristic peak equivalent peak-height ratios ( $/ \mathrm{c}-\mathrm{H} / \mathrm{I}_{\mathrm{C}=\mathrm{C}}$ ) (Santamaría et al., 2010; Cadrazco et al., 2019).

The influence of fuel with different blending ratios on the surface $\mathrm{C}-\mathrm{H}$ functional groups of exhaust PM is shown in Fig. 5. The ratio of $I_{\mathrm{C}-\mathrm{H}} / \mathrm{I}_{\mathrm{C}=\mathrm{C}}$ of $\mathrm{PODE}_{2-4} / \mathrm{diesel}$ blends is within the range of $0.13-0.27$ at low load and $0.07-0.18$ at high load. As the proportion of PODE $2-4$ additives increases, the ratio of $I_{\mathrm{C}-\mathrm{H}} / I_{\mathrm{C}=\mathrm{C}}$ decreases, and the aliphatic $\mathrm{C}-\mathrm{H}$ functional groups on the surface of PM decrease. These results may occur because with increased PODE2-4 concentration, the oxygen content will increase accordingly. More oxygen will make PM oxidize more completely and reduce the content of C-H aliphatic functional groups (Fayad et al., 2020).

\subsection{Results of the XPS Analysis}

\subsubsection{Oxygen-to-carbon elemental ratio}

Using survey scans, XPS can obtain the composition and content information of the surface 


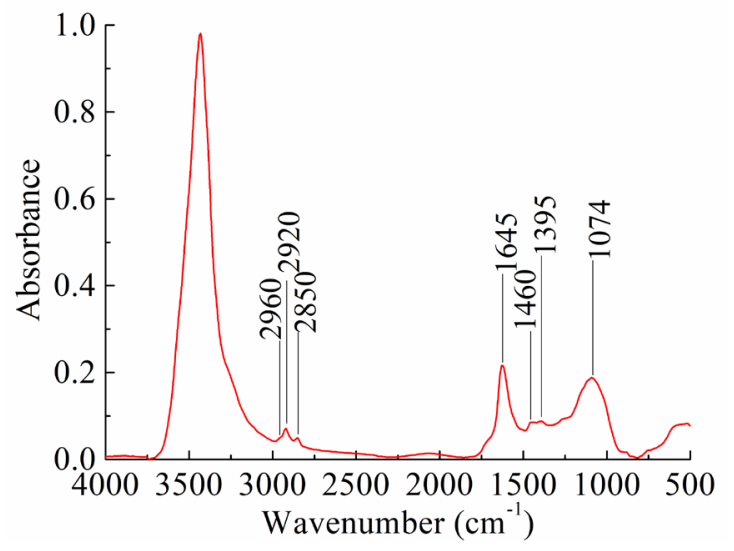

Fig. 4. FTIR spectrum of PO exhaust particles under high load.

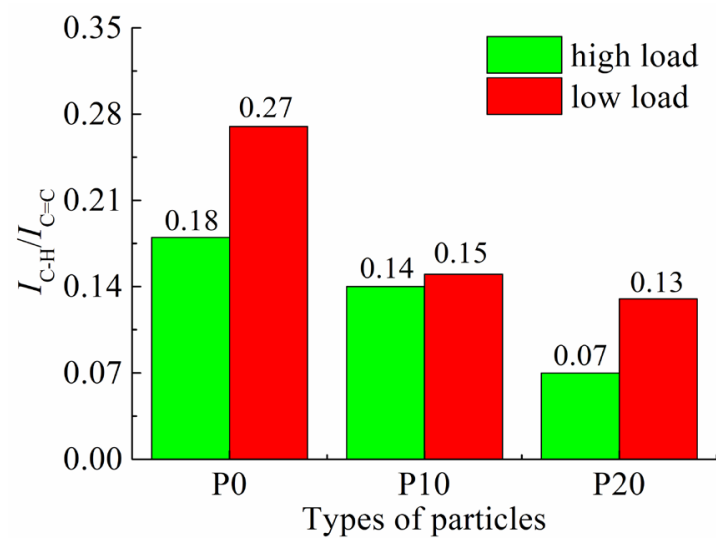

Fig. 5. $I_{C-H} / I_{C=C}$ ratio of PM samples surface.

elements of PM. The major ingredients of $\mathrm{PODE}_{2-4} /$ diesel fuel exhaust PM with different blending proportions collected in this paper are carbon, followed by oxygen, as shown in Fig. 6.

Fig. 7 shows that the $\mathrm{O} / \mathrm{C}$ ratio of the $\mathrm{PODE}_{2-4} /$ diesel blends is $0.246-0.308$ at low load and 0.126-0.136 at high load. The $\mathrm{O} / \mathrm{C}$ ratio increases as the $\mathrm{PODE}_{2-4}$ blending proportion increases, which may be caused by the higher oxygen content of the additive itself.

\subsubsection{Different forms of hybrid carbon}

The composition information of carbon atoms can be obtained by narrow scans of C. XPS Peak 4.1 software was used to fit the carbon spectrum and Gauss-Lorenz peak fitting method (Mustafi et al., 2010) was used to fit the carbon spectrum into four small peaks, $\mathrm{sp}^{2}, \mathrm{sp}^{3}$, hydroxyl (C-OH) and carbonyl $(\mathrm{C}=\mathrm{O})$ groups. The corresponding binding energies are near $284.8 \mathrm{eV}, 285.4 \mathrm{eV}$, $286.6 \mathrm{eV}$ and $288.8 \mathrm{eV}$, as shown in Fig. 8, which shows that diesel exhaust particles primarily exist in the form of $\mathrm{sp}^{2}$ and $\mathrm{sp}^{3}$ hybrids, of which $\mathrm{sp}^{2}$ is the dominant form. An increase in $\mathrm{sp}^{2}$ content means a strong order degree of $\mathrm{PM}$, while an increase in $\mathrm{sp}^{3}$ content means a strong disorder degree of PM. Therefore, with an increase in the $\mathrm{sp}^{3} / \mathrm{sp}^{2}$ ratio, the disorder degree of PM will also increase (Vander Wal et al., 2010), and the higher the degree of carbon structural disorder is, the easier it is to oxidize.

Fig. 9 shows the variation of the hybrid ratio of the P0, P10 and P20 exhaust particles under high and low loads. Considering the variation regularity of $\mathrm{sp}^{3} / \mathrm{sp}^{2}$ ratio under low load and high load shown in Fig. 9, the $\mathrm{sp}^{3} / \mathrm{sp}^{2}$ ratio of $\mathrm{PODE}_{2-4} /$ diesel blended fuel exhaust PM is $0.607-0.762$ and $0.368-0.678$, respectively, and the $\mathrm{sp}^{3} / \mathrm{sp}^{2}$ ratio increases with increasing $\mathrm{PODE}_{2-4}$ concentration.

These results likely occur because as the concentration of $\mathrm{PODE}_{2-4}$ increases, the oxygen content of the blended fuel also increases, and the oxygen component can promote the oxidative decomposition of the exhaust PM, resulting in a shorter length of microcrystalline carbon, and 


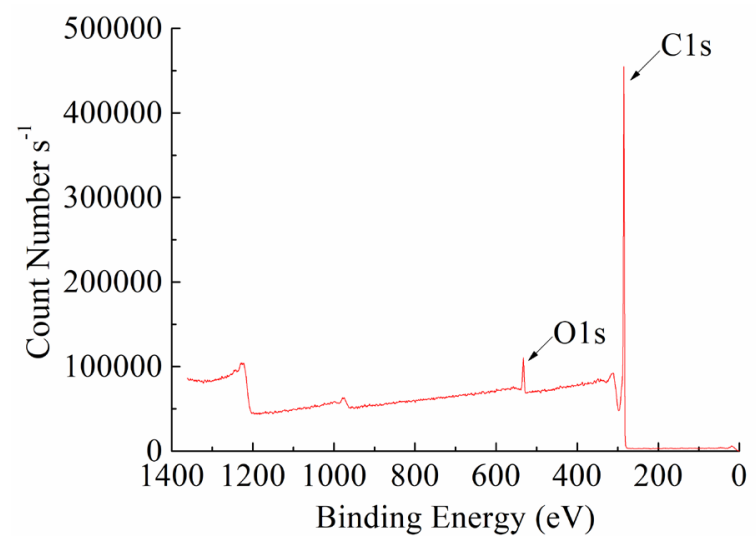

Fig. 6. XPS survey scans of PO exhaust particles under high load.

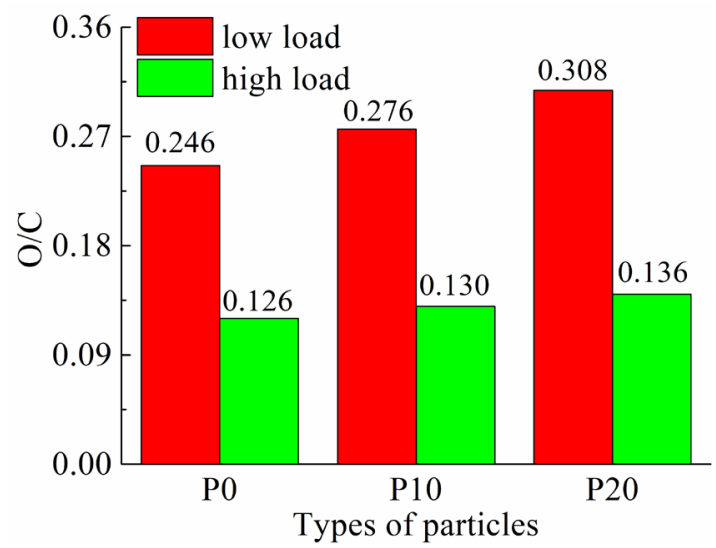

Fig. 7. Variation regularity of $\mathrm{PM}$ samples $\mathrm{O} / \mathrm{C}$ radio.

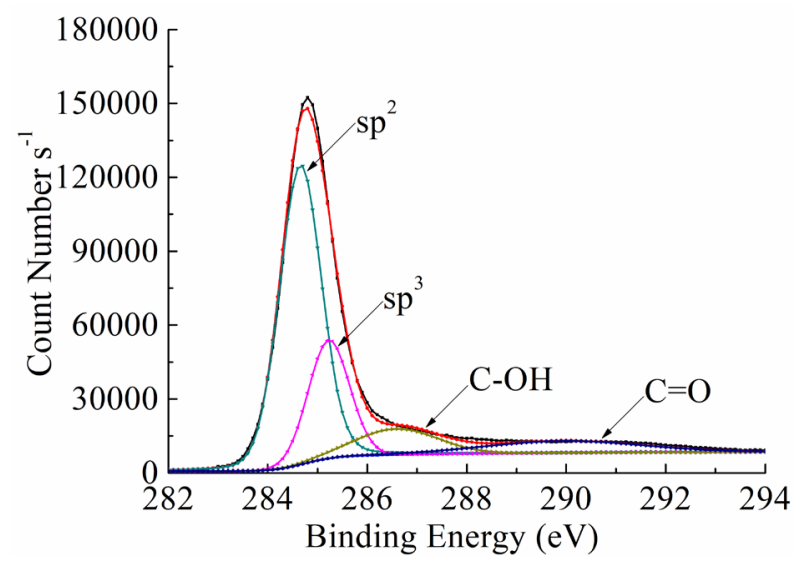

Fig. 8. Narrow scans of PO exhaust particles element $C$ under high load.

enhancing the disorder of the carbon structure. Thus, the increase in the blended fuel oxygen content increases the $\mathrm{PM} \mathrm{sp} / \mathrm{sp}^{2}$ ratio.

\subsection{3 $\mathrm{C}-\mathrm{OH}$ and $\mathrm{C}=\mathrm{O}$ oxygen-containing functional groups}

Fig. 10 shows the percentage content of oxygen-containing functional groups in the exhaust PM of blended fuel under high and low loads. Results show that the percentage content of $\mathrm{C}-\mathrm{OH}$ is between $2.21 \%$ and $2.52 \%$; the content of $\mathrm{C}=\mathrm{O}$ is between $1.88 \%$ and $2.25 \%$; and the content of total oxygen-containing functional groups is between $4.09 \%$ and $4.77 \%$ at low load. Under high 


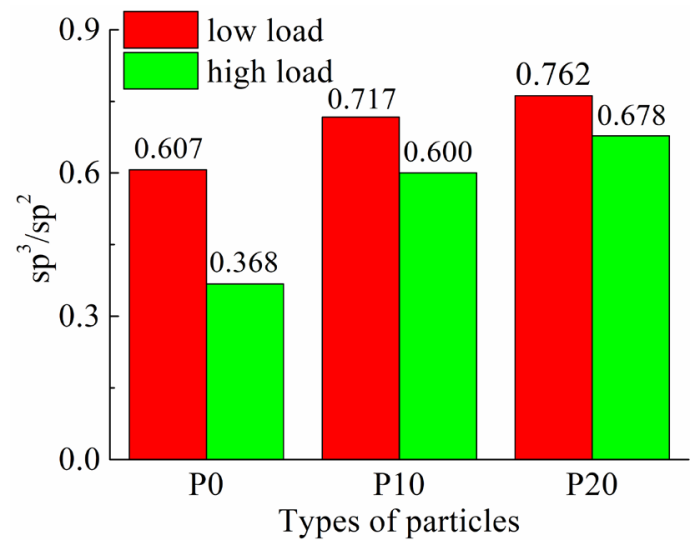

Fig. 9. Variation regularity of $\mathrm{PM}$ samples $\mathrm{sp}^{3} / \mathrm{sp}^{2}$ ratio.
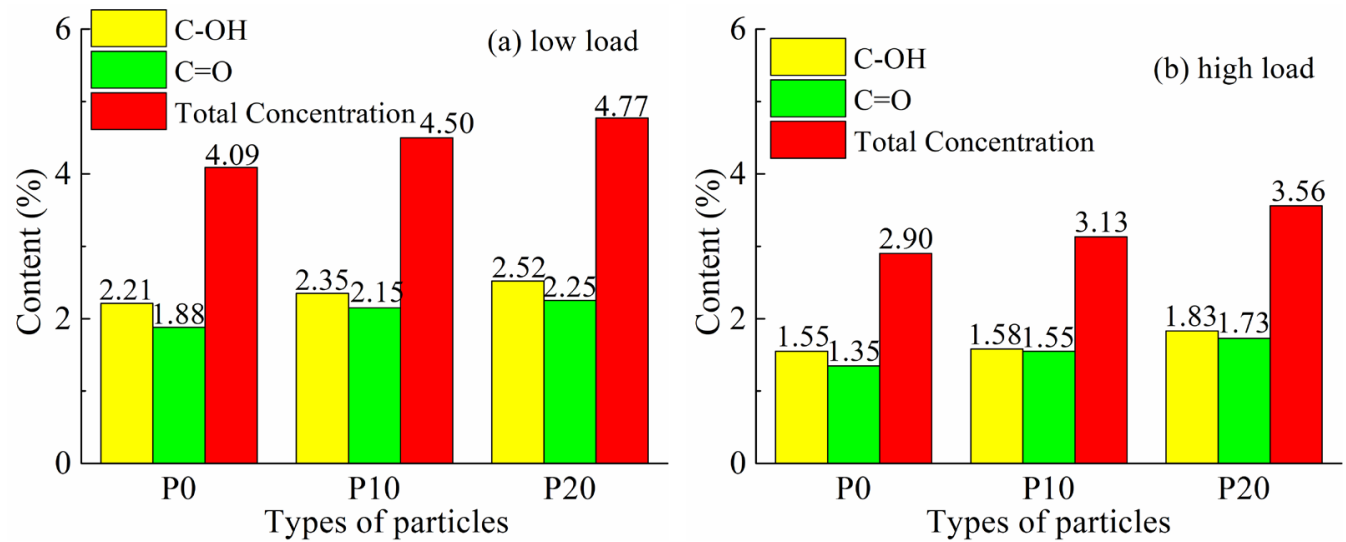

Fig. 10. Variation regularity of PM samples oxygen-containing functional groups.

load, the percentage content of $\mathrm{C}-\mathrm{OH}$ ranged from $1.55 \%$ to $1.83 \%$; the content of $\mathrm{C}=\mathrm{O}$ ranged from $1.35 \%$ to $1.73 \%$; and the content of total oxygen-containing functional groups ranged from $2.90 \%$ to $3.56 \%$. With increasing $\mathrm{PODE}_{2-4}$ blending proportion, the percentage contents of $\mathrm{C}-\mathrm{OH}$, $\mathrm{C}=\mathrm{O}$ and total oxygen-containing functional groups $(\mathrm{C}-\mathrm{OH}$ and $\mathrm{C}=\mathrm{O})$ of the $\mathrm{PM}$ all increased.

These results likely occurred because an increase in oxygen levels can enhance the disorder of PM (Savic et al., 2016). When the disordered degree of PM improves, the surface will have a shorter microcrystalline length and more irregular cross-section, which can increase the number of chemical reaction activation sites. The combination of active oxygen-containing groups and PM in the combustion process becomes easier, making the surface of exhaust PM form a stable oxygen-containing functional group. In addition, the oxygen in the fuel itself more easily participates in the oxidation reaction than the oxygen in air, which increases the number of oxygen-containing groups in the combustion process, thus improving the probability of forming oxygen-containing functional groups on the surface of PM.

\section{CONCLUSIONS}

(1) TEM analysis indicated that the overall PM size decreased, and the arrangement of PM became looser with increasing $\mathrm{PODE}_{2-4}$ concentration. In addition, the number of branched chains and primary particles also decreased markedly, and the chain length shortened.

(2) Fractal theory showed that the fractal dimension was 1.58-1.79 for blended fuel's PM, and the fractal dimension of PM increased as the PODE $2-4$ blending ratio increased.

(3) FTIR analysis found that the ratio of $I_{C-H} / I_{C=C}$ of the blended fuel was $0.07-0.27$. The ratio $I_{C-H} / I_{C=C}$ and the aliphatic $\mathrm{C}-\mathrm{H}$ functional group on the surface of $\mathrm{PM}$ also decreased with an increasing $\mathrm{PODE}_{2-4}$ blending ratio. 
(4) XPS analysis presented that the $\mathrm{O} / \mathrm{C}$ ratio of the blended fuel was $0.126-0.308$, the $\mathrm{sp}^{3} / \mathrm{sp}^{2}$ ratio was between $0.368-0.762$, and the contents of $\mathrm{C}-\mathrm{OH}, \mathrm{C}=\mathrm{O}$ and total oxygen-containing functional groups were $1.55 \%-2.52 \%, 1.35 \%-2.25 \%$ and $2.90 \%-4.77 \%$, respectively. With an increasing $\mathrm{PODE}_{2-4}$ blending ratio, the contents of $\mathrm{O} / \mathrm{C}, \mathrm{sp}^{3} / \mathrm{sp}^{2}, \mathrm{C}-\mathrm{OH}, \mathrm{C}=\mathrm{O}$ and total oxygencontaining functional groups of the PM increased.

\section{ACKNOWLEDGMENTS}

The authors would like to acknowledge financial support provided by National Natural Science Foundation of China (51505275).

\section{DISCLAIMER}

The authors declare no conflict of interest.

\section{SUPPLEMENTARY MATERIAL}

Supplementary material for this article can be found in the online version at https://doi. org/10.4209/aaqr.210175

\section{REFERENCES}

Atzei, D., Fantauzzi, M., Rossi, A., Fermo, P., Piazzalunga, A., Valli, G., Vecchi, R. (2014). Surface chemical characterization of $\mathrm{PM}_{10}$ samples by XPS. Appl. Surf. Sci. 307, 120-128. https://doi.org/ 10.1016/j.apsusc.2014.03.178

Awad, O.I., Mamat, R., Noor, M.M., Ibrahim, T.K., Yusri, I.M., Yusop, A.F. (2018). The impacts of compression ratio on the performance and emissions of ice powered by oxygenated fuels: $A$ review. J. Energy Inst. 91, 19-32. https://doi.org/10.1016/j.joei.2016.09.003

Brasil, A.M., Farias, T.L., Carvalho, M.G. (1999). A recipe for image characterization of fractal-like aggregates. J. Aerosol Sci. 30, 1379-1389. https://doi.org/10.1016/s0021-8502(99)00026-9

Cadrazco, M., Santamaría, A., Agudelo, J.R. (2019). Chemical and nanostructural characteristics of the particulate matter produced by renewable diesel fuel in an automotive diesel engine. Combust. Flame 203, 130-142. https://doi.org/10.1016/j.combustflame.2019.02.010

Chen, H.Y., Wang, M.F., Wang, X., Li, D.Q., Pan, Z.X., Bae, C. (2020). Experimental investigation of particulate matter structures under partially premixed combustion in a compression ignition engine. Fuel 259, 116286. https://doi.org/10.1016/j.fuel.2019.116286

Chen, Y.C., Weng, Y.H., Chiu, Y.W., Yang, C.Y. (2015). Short-term effects of coarse particulate matter on hospital admissions for cardiovascular diseases: A case-crossover study in a tropical city. J. Toxicol. Environ. Health A 78, 1241-1253. https://doi.org/10.1080/15287394.2015.1083520

Di, Q., Wang, Y., Zanobetti, A., Wang, Y., Koutrakis, P., Choirat, C., Dominici, F., Schwartz, J.D. (2017). Air pollution and mortality in the medicare population. N. Engl. J. Med. 376, 25132522. https://doi.org/10.1056/NEJMoa1702747

Fayad, M.A., Tsolakis, A., Martos, F.J. (2020). Influence of alternative fuels on combustion and characteristics of particulate matter morphology in a compression ignition diesel engine. Renew. Energy 149, 962-969. https://doi.org/10.1016/j.renene.2019.10.079

Gao, W., Liu, J., Sun, P., Yang, C., Fang, J. (2019). Gaseous emissions and particle microstructure characteristics of PODE/diesel blend fuel. Int.J Automot. Technol. 20, 607-617. https://doi.org/ 10.1007/s12239-019-0058-z

Guascito, M.R., Cesari, D., Chirizzi, D., Genga, A., Contini, D. (2015). XPS surface chemical characterization of atmospheric particles of different sizes. Atmos. Environ. 116, 146-154. https://doi.org/10.1016/j.atmosenv.2015.06.028

Kellerer, H., Koch, R., Wittig, S. (2000). Measurements of the growth and coagulation of soot particles in a high-pressure shock tube. Combust. Flame 120, 188-199. https://doi.org/10.101 6/S0010-2180(99)00067-X 
Köylü, Ü.Ö., Faeth, G.M., Farias, T.L., Carvalho, M.G. (1995). Fractal and projected structure properties of soot aggregates. Combust. Flame 100, 621-633. https://doi.org/10.1016/00102180(94)00147-k

Lapuerta, M., Ballesteros, R., Martos, F.J. (2006). A method to determine the fractal dimension of diesel soot agglomerates. J. Colloid Interface. Sci. 303, 149-158. https://doi.org/10.1016/j.jcis. 2006.07.066

Lapuerta, M., Sánchez-Valdepeñas, J., Barba, J., Fernández-Rodríguez, D., Andrés, J.P., García, T. (2019). Analysis of soot from the use of butanol blends in a Euro 6 diesel engine. Energy Fuel 33, 2265-2277. https://doi.org/10.1021/acs.energyfuels.8b04083

Li, M.D., Zhao, Y., Fang, J., Zhao, S.Y., Xu, G.J., Wang, Z. (2019). Effect of dimethyl carbonate on the micromorphology and structure of combustion particles from diesel engines. Energy Source Part A 42, 1155-1165. https://doi.org/10.1080/15567036.2019.1602225

Li, R.N., Wang, Z. (2018). Study on status characteristics and oxidation reactivity of biodiesel particulate matter. Fuel 218, 218-226. https://doi.org/10.1016/j.fuel.2018.01.041

Li, Z., Wen, Q., Zhang, R. (2017). Sources, health effects and control strategies of indoor fine particulate matter (PM2.5): A review. Sci. Total Environ. 586, 610-622. https://doi.org/10.1016/ j.scitotenv.2017.02.029

Liu, H.Y., Wang, Z., Wang, J.X., He, X., Zheng, Y.Y., Tang, Q., Wang, J.F. (2015). Performance, combustion and emission characteristics of a diesel engine fueled with polyoxymethylene dimethyl ethers (PODE 3 -4)/diesel Blends. Energy 88, 793-800. https://doi.org/10.1016/j.energ y.2015.05.088

Maricq, M.M., Xu, N. (2004). The effective density and fractal dimension of soot particles from premixed flames and motor vehicle exhaust. J. Aerosol Sci. 35, 1251-1274. https://doi.org/10. 1016/j.jaerosci.2004.05.002

Mustafi, N.N., Raine, R.R., James, B. (2010). Characterization of exhaust particulates from a dual fuel engine by TGA, XPS, and Raman techniques. Aerosol Sci. Technol. 44, 954-963. https://doi.org/10.1080/02786826.2010.503668

Nayyar, A., Sharma, D., Soni, S.L., Bhardwaj, B., Augustine, M. (2019). Modeling and experimental investigation for performance and emissions on a diesel engine using bio-oxygenated ternary fuel blends. Energy 168, 136-150. https://doi.org/10.1016/j.energy.2018.11.098

Omidvarborna, H., Kumar, A., Kim, D.S. (2016). Variation of diesel soot characteristics by different types and blends of biodiesel in a laboratory combustion chamber. Sci. Total Environ. 544, 450459. https://doi.org/10.1016/j.scitotenv.2015.11.076

Qu, L., Wang, Z., Zhang, J. (2016). Influence of waste cooking oil biodiesel on oxidation reactivity and nanostructure of particulate matter from diesel engine. Fuel 181, 389-395. https://doi.org/ 10.1016/j.fuel.2016.04.113

Ren, S.J., Wang, Z., Li, B.W., Liu, H.Y., Wang, J.X. (2019). Development of a reduced polyoxymethylene dimethyl ethers ( $\left.P O D E_{n}\right)$ mechanism for engine applications. Fuel 238, 208224. https://doi.org/10.1016/j.fuel.2018.10.111

Rouleau, M., Egyed, M., Taylor, B., Chen, J., Samaali, M., Davignon, D., Morneau, G. (2013). Human health impacts of biodiesel use in on-road heavy duty diesel vehicles in Canada. Environ. Sci. Technol. 47, 13113-13121. https://doi.org/10.1021/es4023859

Salamanca, M., Mondragón, F., Agudelo, J.R., Santamaría, A. (2012). Influence of palm oil biodiesel on the chemical and morphological characteristics of particulate matter emitted by a diesel engine. Atmos. Environ. 62: 220-227. https://doi.org/10.1016/j.atmosenv.2012.08.031

Santamaría, A., Yang, N., Eddings, E., Mondragon, F. (2010). Chemical and morphological characterization of soot and soot precursors generated in an inverse diffusion flame with aromatic and aliphatic fuels. Combust. Flame 157, 33-42. https://doi.org/10.1016/j.combustfl ame.2009.09.016

Savic, N., Rahman, M.M., Miljevic, B., Saathoff, H., Naumann, K.H., Leisner, T., Riches, J., Gupta, B., Motta, N., Ristovski, Z.D. (2016). Influence of biodiesel fuel composition on the morphology and microstructure of particles emitted from diesel engines. Carbon 104, 179-189. https://doi.org/10.1016/j.carbon.2016.03.061

Shi, T., Liu, M., Hu, Y., Li, C., Zhang, C., Ren, B. (2019). Spatiotemporal pattern of fine particulate matter and impact of urban socioeconomic factors in China. Int. J. Environ. Res. Public Health 16, 1099. https://doi.org/10.3390/ijerph16071099 
Van Gulijk, C., Marijnissen, J.C.M., Makkee, M., Moulijn, J.A., Schmidt-Ott, A. (2004). Measuring diesel soot with a scanning mobility particle sizer and an electrical low-pressure impactor: Performance assessment with a model for fractal-like agglomerates. J. Aerosol Sci. 35, 633655. https://doi.org/10.1016/j.jaerosci.2003.11.004

Vander Wal, R.L., Bryg, V.M., Hays, M.D. (2010). Fingerprinting soot (towards source identification): Physical structure and chemical composition. J. Aerosol Sci. 41, 108-117. https://doi.org/10.1 016/j.jaerosci.2009.08.008

Wang, D., Zhao, F., Zhu, G.L., Xia, C.G. (2018). Production of eco-friendly poly(oxymethylene) dimethyl ethers catalyzed by acidic ionic liquid: A kinetic investigation. Chem. Eng. J. 334, 26162624. https://doi.org/10.1016/j.cej.2017.11.181

Wang, X.C., Wang, Y., Bai, Y.Q., Wang, P., Zhao, Y.W. (2019). An overview of physical and chemical features of diesel exhaust particles. J. Energy Inst. 92, 1864-1888. https://doi.org/10.1016/j.jo ei.2018.11.006

Xian, M., Wang, K., Lou, H., Wang, Y., Zhang, L., Wang, C. (2019). Short-term haze exposure predisposes healthy volunteers to nasal inflammation. Allergy Asthma Immunol Res. 11, 632643. https://doi.org/10.4168/aair.2019.11.5.632

Yan, F.C., Song, J.N., Zhuang, Y., Qiu, L., Li, Z.J., Meng, Z.W. (2021). Three-dimension soft X-ray tomographic reconstruction of particulates emitted from a diesel engine. J. Aerosol Sci. 156, 105784. https://doi.org/10.1016/j.jaerosci.2021.105784

Yang, H., Li, X.H., Wang, Y., Mu, M.F., Li, X.H., Kou, G.Y. (2016). Pyrolysis characteristic analysis of particulate matter from diesel engine run on diesel/polyoxymethylene dimethyl ethers blends based on nanostructure and thermogravimetry. Aerosol Air Qual. Res. 16, 2560-2569. https://doi.org/10.4209/aaqr.2016.07.0329

Yitshak-Sade, M., Kloog, I., Novack, V. (2017). Do air pollution and neighborhood greenness exposures improve the predicted cardiovascular risk? Environ. Int. 107, 147-153. https://doi.org/10.1016/j.envint.2017.07.011

Zhu, L., Xiao, Y., Cheung, C.S., Guan, C., Huang, Z. (2016). Combustion, gaseous and particulate emission of a diesel engine fueled with n-pentanol ( $\mathrm{C} 5$ alcohol) blended with waste cooking oil biodiesel. Appl. Therm. Eng. 102, 73-79. https://doi.org/10.1016/j.applthermaleng.2016.03.145 